\title{
On-Line Stator Winding Fault Diagnosis in Induction Generators for Renewable Generation
}

\author{
I. Albizu*, A. Tapia**, J. R. Saenz ${ }^{* * *}$, A. J. Mazón ${ }^{*}$ and I. Zamora* \\ * The University of the Basque Country/Dept. of Electrical Engineering, Bilbao, Basque Country \\ ** The University of the Basque Country/Dept. of Control and Systems Engineering, Donostia, Basque Country \\ ${ }^{* *}$ The University of Cadiz/Dept. of Electrical Engineering, Cadiz, Spain \\ igor.albizu@ehu.es
}

\begin{abstract}
Renewable generation systems are increasing its presence in electrical power systems. For this reason, it is more important than ever to count with reliable and secure generation systems. In this way, the use of on-line diagnostic techniques in the maintenance schemes can be useful. This paper is about on-line condition monitoring in induction generators for small hydro stations and wind farms. In particular, stator winding fault diagnosis is analyzed. Currently, there are diagnostic techniques that are used in induction motors, but they could be used in generators as well. This paper analyzes the induction generator characteristics and describes the appropriate diagnostic techniques. These techniques depend on the machine voltage. As most of the induction generators are low voltage machines, the diagnosis of stator winding faults will be based on the detection of inter-turn short circuits. Most of the inter-turn short circuit diagnostic techniques are noninvasive as they are based on voltage and line current monitoring.
\end{abstract}

\section{INTRODUCTION}

Renewable energy generation, particularly energy from wind, water, solar power and biomass is a central object of current energy policies. Renewable energy has an important role to play in reducing $\mathrm{CO}_{2}$ emissions. It also helps to improve the security of energy supply by reducing the dependence on imported energy sources. Renewable energy sources are expected to be economically competitive with conventional energy sources in the medium to long term.

Several types of electrical power generation sources are emerging with different degrees of development and future prospective but currently, wind generation is increasing its presence in an amazing way, due to several characteristics: the production has zero fuel cost, it is environmentally clean and the total energy production can be quite important. Hence, wind energy has turned out to be one of the most important and promising sources of renewable energy. The installed wind power increase expectations for the next few years are high. This energy source will represent a significant proportion of total installed power in the power system.

Small hydro is a proven technology, which has now reached maturity. Ideal for electrification of remote sites, it also serves as a complement to national electrical production in the case of strong demand and consumption.

Both wind and hydro systems convert renewable energy into mechanical energy first and into electrical energy afterwards. The electric generators can be either asynchronous or synchronous.
Among the electric rotating machines, induction machines have a special importance. Due to their simplicity and robustness inductions motor are the most used in industry. Current developments of electric drives based on power electronics for variable speed applications have strengthened the supremacy of the induction motors. Furthermore, with the current developments of renewable generation, the use of induction machines as generators is getting bigger and bigger. So far, the induction generators have been used in small hydro plants. Nevertheless, the main increase has come with the growth of installed wind generators.

Studies carried out have shown that behind the bearing faults the most common fault of induction motors are related to stator faults. Between $30 \%$ and $40 \%$ of the faults in induction motors occur in the stator winding. Stator faults begin with the degradation of the insulation between turns and the consequent inter-turn short circuit.

The operators of electrical systems are under pressure to reduce maintenance costs and prevent unscheduled downtimes. For this reason, on-line diagnostic techniques in parallel with conventional planned maintenance schemes are useful. In the past years, many techniques have been developed for the diagnosis of induction motors. There are commercial systems for the diagnosis of mechanical problems, broken rotor bars and stator faults.

When performing the stator fault diagnosis, the diagnostic approach depend on the voltage level of the machine. If the voltage is high enough it is possible to apply the approach based on the monitoring of partial discharges. If this is not the case, it is necessary to use the approach based on the detection of short-circuited turns.

The object of this paper is to study the application of induction motor stator winding fault diagnostic techniques to induction generators. For this purpose, the electrical characteristics of the induction generators will be analyzed first and the diagnostic techniques will be discussed afterwards.

\section{INDUCTION GENERATORS FOR RENEWABLE GENERATION}

\section{A. Induction Generators for Wind Generators}

The first wind generators installed worked with fixed speed. This system makes use of low voltage $(690 \mathrm{~V})$ asynchronous generators with cage rotor that work in oversynchronous operation. One drawback of this machine is that requires the stator to be magnetized from the grid. In order to facilitate the magnetization, capacitor banks are installed. 
It is a very useful mechanical property that the generator will increase or decrease its speed slightly if the torque varies. This means that there will be less wear on the gearbox. For this reason, the current trend is toward variable speed wind generators. Currently, there are two technologies competing with each other. The first technology is based on variable speed synchronous generators. The second technology is based on doubly-fed induction machines (DFIM).

Doubly-fed induction generators used in wind generators are low voltage $(690 \mathrm{~V})$ and variable speed machines. The slip-ring rotor is supplied from a PWM converter and the stator is connected directly with the supply grid. The control of active and reactive power is carried out independently using vector control techniques. As well as normal oversynchronous operation, undersynchronous generator states can also be achieved. Currently, the electric power of the machines is between $660 \mathrm{~kW}$ and $2 \mathrm{MW}$.

\section{B. Induction Generators for Small Hydro}

Synchronous generators are more expensive than asynchronous generators and are used in power systems where the output of the generator represents a substantial proportion of the power system load. Asynchronous generators are cheaper and are used in large grids where their output is an insignificant proportion of the power system load. Their efficiency is 2 to 4 per cent lower than the efficiency of synchronous generators over the entire operating range. In general, when the power exceeds 5000 $\mathrm{kVA}$ a synchronous generator is installed.

Induction generators are simple squirrel-cage induction motors with no possibility of voltage regulation. They draw their excitation current from the network. Adding a bank of capacitors can compensate for the absorbed reactive energy.

The working voltage of the generator varies with its power. The standard generation voltages are $200 \mathrm{~V}$ or 400 $\mathrm{V}$ up to $1400 \mathrm{kVA}$, and $6000 / 6600 \mathrm{~V}$ for higher installed power up to $5000 \mathrm{kVA}$.

\section{ON-LINE STATOR WINDING FAULT DIAGNOSIS}

The main cause of winding faults is the degradation of the insulation [1]. Although the ageing process and the surface contamination are causes of degradation, the vibration is the major cause of premature degradation. Another cause of degradation is the use of PWM converters.

The faults start with turn-to-turn short circuits within a coil. After this, more serious faults can be developed: short circuit between coils of the same phase, phase to phase short circuit, phase to earth short circuit, and open circuit in one phase.

The diagnostic strategy depends on the voltage level [2]. If the voltage level is above $4.1 \mathrm{kV}$, it is possible to apply the partial discharge monitoring approach. The identification of the deterioration of the insulation allows repairing it before failure. This is not possible if the voltage level is below $4.1 \mathrm{kV}$. In this case, the first indication of a problem will be that a fault actually develops. Hence, below $4.1 \mathrm{kV}$, the diagnostic strategy consists on the detection of inter-turn short circuits within a coil.

\section{A. Fault Diagnosis in Induction Generators for Renewable Generation}

Most of the asynchronous generators for renewable generation are low voltage machines. Only the generators for small hydro with considerable power are in the medium voltage level.

The voltage level of the machine is a factor that determines the diagnostic strategy. The diagnosis is much easier in the case that partial discharges are present in the insulation. But this phenomenon only appears when the voltage level is above $4.1 \mathrm{kV}$. Therefore, for most of the generators the diagnostic strategy will consist on the detection of inter-turn short circuits.

In the case that the generator voltage is above $4.1 \mathrm{kV}$, partial discharge monitoring can identify insulation degradation prior to complete breakdown. The technique is widely applied in industry $[3,4]$.

For the generators with voltage below $4.1 \mathrm{kV}$, the diagnosis is based on the detection of inter-turn short circuits. Although considerable research has been carried out, the diagnosis of inter-turn short circuits is not a mature technique yet. In the following section, a revision of these techniques is presented.

\section{B. On-Line Inter-Turn Fault Diagnosis}

An inter-turn short circuit produce some changes in the electrical magnitudes of the machine. The current that circulates in the short-circuited turns changes the air gap magnetic flux and consequently the induced currents. The axial leakage flux that appears due to inherent small asymmetries of the machine is also influenced by the fault. For this reason, there are some diagnostic techniques that are based on the signature analysis of currents and fluxes in order to detect the changes on the spectra.

The inter-turn short circuit produces an asymmetry of the stator winding. For this reason the negative-sequence components of electrical magnitudes such as currents, voltages or impedances show a change of their values when a fault occurs. Hence, some techniques are based on the detection of changes in the negative-sequence components. These techniques have to overcome some difficulties due to the effects of supply unbalances, sensor asymmetries and machines inherent asymmetries in the negative-sequence components.

\section{1) Axial Flux Signature Analysis}

It has been shown that axial flux monitoring can detect inter-turn short circuits [5-8]. The perfect electrical machine does not produce any axial flux because the currents flowing in the end windings of both the rotor and stator circuits are perfectly balanced. However, there are always small asymmetries in both the material and geometric aspects of the magnetic and electric circuits of any machine. This results in every machine producing a small, but measurable axial leakage flux.

Both stator and rotor windings produce axial leakage flux that are a result of the winding currents. Hence, the axial leakage flux spectral content may be related directly to the harmonic components present in the winding currents. These components depend on the harmonic components of the air gap flux.

A stator inter-turn short circuit changes the distribution of the MMF in the air gap because of the current that circulates through the short-circuited turns. The MMF 
distribution due to the inter-turn short circuit induces the following new frequencies in the rotor currents and so in the axial leakage flux,

$$
(k \pm n(1-s) / p) f
$$

where $f$ is the fundamental frequency of the supply, $k$ is the supply voltage harmonic order, $p$ is the number of pole pairs, $s$ is the fractional slip and $n$ is an integer different from $2 p m$ for $m=1,2,3, \ldots$

If a coil is wound around the shaft of the machine, it will have induced in it a voltage which can be related to the axial flux. The main drawback is that the search coil is invasive to the motor's environment. Furthermore, results have shown that components in the axial flux that are indicative of shorted turns are also very load dependent. This can be a problem for reliable diagnosis.

\section{2) Current Signature Analysis}

The line current spectrum is also influenced by the inter-turn short circuit. Line current monitoring is less invasive to the machine's environment and the harmonics can be used as fault indicator [9-12]. The main drawback of this approach is the difficulty to evaluate the fault severity.

\section{3) Current Negative-Sequence Component}

An inter-turn fault in the stator winding leads to an asymmetry between the three phases, leading to a negative-sequence component in the line current $[13,14]$. However, inherent machine asymmetries, unbalanced supply voltages and mismatched instrumentation gains produce a similar effect. These factors have to be taken into account in the fault detection strategy.

In the method proposed in [15], a feed-forward neural network (FFNN) is proposed for the diagnosis. Simulation data is used to train the neural network. The supply voltage is supposed to be symmetric. As the model does not consider the real-life asymmetries, the results obtained are not reliable.

In [16] another diagnostic approach based on a FFNN is proposed, but in this case the asymmetries are taken into account. The NN is trained with the sequence-components of the voltage and the positive-sequence component of the current to estimate the negative-sequence component of the current. In the monitoring phase this estimated value is compared with the measured value. A deviation will be an indication of fault. The FFNN is trained off-line over the entire range of operation conditions expected. This scheme, known as global minimum training (GMT) is not suitable for practical implementation, as it requires considerable data memory and computation. For this reason a continual on-line training (COT) algorithm was proposed [17]. This algorithm has lower computation and data storage requirements, but if the fault develops slowly, this is not detected.

The monitoring of the current negative-sequence component $\left(\mathrm{I}_{\mathrm{a} 2}\right)$ is easy as it is calculated from the measurements of the three line currents. However, its application for fault diagnosis is difficult because of the current negative-sequence component due to other factors apart from the fault. Nevertheless, in $[18,19]$ the negativesequence current is used as fault indicator. The negativesequence current component due to the machine inherent asymmetries and the asymmetry of the sensors is calculated and subtracted so that the fault alone can be monitored. This value depends on the load. For this reason it must be calculated and stored as a function of the voltage and load, which complicates the method.

\section{4) Effective Negative-Sequence Impedance}

Due to the difficulties associated to the negativesequence current, a different fault indicator was proposed [20-22]. It is known as effective negative-sequence impedance $\left(\mathrm{Z}_{\mathrm{a} 2 \mathrm{eff}}\right)$.

$$
Z_{a 2 e f f}=\frac{V_{a 2}}{I_{a 2}}
$$

The calculation of this indicator is simple and its value is practically insensitive to the operating speed value. However, it is not possible to evaluate the fault severity and the machine and sensors asymmetries decrease considerably the sensitivity of the indicator.

\section{5) Voltage Mismatch}

Due to these limitations, a different fault indicator has been proposed. It is known as voltage mismatch detector and it is based on the deviation of the voltage sequence components due to the fault $[23,24]$. In the following paragraphs, the theoretical development of the method will be described.

It may be shown that the relation between voltage and current sequence components is as indicated in equation (3).

$$
\begin{aligned}
& V_{a 0}=z_{00} I_{a 0}+z_{01} I_{a 1}+z_{02} I_{a 2} \\
& V_{a 1}=z_{10} I_{a 0}+z_{11} I_{a 1}+z_{12} I_{a 2} \\
& V_{a 2}=z_{20} I_{a 0}+z_{21} I_{a 1}+z_{22} I_{a 2}
\end{aligned}
$$

The $\mathrm{z}_{\mathrm{xy}}$ parameters depend on the motor design and construction, the operating speed and the presence of a winding fault.

Assuming that the zero-sequence component of the line current is equal to zero $\left(I_{a 0}=0\right)$ :

$$
\begin{aligned}
& V_{a 1}=Z_{11} I_{a 1}+Z_{12} I_{a 2} \\
& V_{a 2}=Z_{21} I_{a 1}+Z_{22} I_{a 2}
\end{aligned}
$$

The values of $\mathrm{z}_{11}, \mathrm{z}_{12}, \mathrm{z}_{21}$ and $\mathrm{z}_{22}$ are calculated from two independent tests for several machine speed values. Monitoring the voltage and line current, $\mathrm{V}_{\mathrm{a} 1}, \mathrm{~V}_{\mathrm{a} 2}, \mathrm{I}_{\mathrm{a} 1}$ and $I_{a 2}$ may be calculated. From $I_{a 1}, I_{a 2}$ and equation (4) the expected values of $\mathrm{V}_{\mathrm{a} 1}$ and $\mathrm{V}_{\mathrm{a} 2}$ are obtained and compared with the measured ones. If an inter-turn short circuit occurs the $\mathrm{z}_{\mathrm{xy}}$ parameters change and a voltage mismatch is observed. This deviation is used as fault indicator.

This fault indicator is independent of the machine and sensors inherent asymmetries because these effects are considered when the $\mathrm{z}_{\mathrm{xy}}$ parameters are calculated. For this reason, the same sensors have to be used during the condition monitoring. The method is also independent of unbalances in the power supply.

A similar approach is proposed in [25]. In this case, the fault indicators are the $\mathrm{z}_{\mathrm{xy}}$ parameter values of equation (4). 


\section{CONCLUSIONS}

Most of the induction generators for renewable generation are low voltage machines. The diagnosis of stator winding faults in low voltage machines is based on the detection of inter-turn short circuits. For this reason, the inter-turn short circuit diagnostic techniques proposed in the literature have been presented.

The trend is toward a non-invasive diagnosis. As a consequence, most of the techniques are based on voltage and line current measurements. As the diagnostic techniques are non-invasive, they are suitable for the implementation in existing installations.

The proposed techniques are still in development and there is not any commercial system available. Furthermore, experimental work with induction generators should be carried out in order to take into account the particularities of each generator type. Nevertheless, these techniques are very promising.

\section{REFERENCES}

[1] Bonnett A H, Soukup G C, "Cause and analysis of stator and rotor failures in three-phase squirrel-cage induction motors", IEEE Transactions on Industrial Applications, Vol. 28, July/August, pp. 921-37, 1992

[2] Thomson W T, “A review of on-line condition monitoring techniques for three-phase squirrel-cage induction motors - past present and future", IEEE Symposium on Diagnostics for Electrical Machines, Power Electronics and Drives SDEMPED’99, pp. 3-18, Gijón (Spain), 1999.

[3] Edwards D G, "On-line diagnosis of defects in the stator winding structures of high voltage rotating machines", International Conference on Electrical Machines ICEM’92, Manchester, 1992.

[4] Stone G C, Sedding H G, Costello M J, “Application of partial discharge testing to motor and generator stator winding maintenance", IEEE Transactions on Industry Applications, Vol. 32, No. 2, pp. 459-464, 1996.

[5] Penman J, Sedding H G, Lloyd B A, Fink W T, "Detection and location of interturn short circuits in the stator windings of operating motors”, IEEE Transactions on Energy Conversion, Vol. 9, No. 4, December, pp.652-658, 1994.

[6] Cabanas M F, Melero M G, Orcajo G A, Faya F R, Solares J, "Experimental application of axial leakage flux to the detection of rotor asymmetries, mechanical anomalies and inter-turn short circuits in working induction motors”, International Conference on Electrical Machines ICEM'98, Istambul, 1998.

[7] Melero M G, Cabanas M F, Rojas C H, Orcajo G A, Cano J M, Solares J, "Study of an induction motor working under stator winding inter-turn short circuit condition", IEEE Symposium on Diagnostics for Electrical Machines, Power Electronics and Drives SDEMPED'03, Atlanta, 2003.

[8] Henao H, Demian C, Capolino G A, “A frequency-domain detection of stator winding faults in induction machines using an external flux sensor", IEEE Transactions on Industry Applications, Vol. 39, No. 5, pp. 1272-1279, 2003.

[9] Thomson W T, "On-line MCSA to diagnose shorted turns in low voltage stator windings of 3-phase induction motors prior to failure", IEEE International Electric Machines and Drives Conference Record IEMDC'01, pp. 891-898, Boston, 2001.
[10] Stavrou A, Sedding H G, Penman J, "Current monitoring for detecting inter-turn short circuits in induction motors", IEEE Transactions on Energy Conversion, Vol. 16, No. 1, March, pp. 32-37, 2001.

[11] Joksimovic G M, Penman J, "The detection of inter-turn short circuits in the stator windings of operating motors", IEEE Transactions on Industrial Electronics, Vol. 47, No. 5, October, pp. 1078-84, 2000.

[12] Nandi S, Toliyat H, "Novel frequency-domain-based technique to detect stator interturn faults in induction machines using statorinduced voltages after switch-off”, IEEE Transactions on Industry Applications, Vol. 38, No. 1, pp. 101-109, 2002.

[13] Williamson S, Mirzoian K, "Analysis of cage induction motors with winding faults”, IEEE-PAS, Vol. 104, No. 7, July, pp. 183842, 1985.

[14] Toliyat H A, Lipo T A, "Transient analysis of cage induction machines under stator, rotor bar and end ring faults”, IEEE Transactions on Energy Conversion, Vol. 10, No. 2, pp. 241-47, 1995.

[15] Filippetti F, Franceschini G, Tassoni C, Ometto A, Meo S, "Recent developments of induction motor drives fault diagnosis using AI techniqes”, IEEE Transactions on Industrial Electronics, Vol. 47, No. 5, October, pp. 994-1004, 2000.

[16] Tallam R M, Habetler T G, Harley R G, Gritter D J, Burton B, "Neural network based stator winding turn-fault detection for induction motors", Conference Record of the IEEE Industry Applications Society, Vol. 1, pp. 375-80, Roma, 2000

[17] Tallam R M, Habetler T G, Harley R G, "Self-Commisioning Training Algorithms for Neural Networks with Applications to Electric Machine Fault Diagnostics”, IEEE Transactions on Power Electronics, Vol. 17, No. 6, pp. 1089-95, 2002.

[18] Kliman G B, Premerlani W J, Koegl R A, Hoeweler D, “A new approach to on-line turn fault detection in ac motors”, Conference Record of the IEEE Industry Applications Society, Vol. 1, pp. 68793, San Diego, 1996.

[19] Kliman G B, Premerlani W J, Koegl R A, Hoeweler D, "Sensitive, on-line turn-to-turn fault detection in AC motors", Electric Machines and Power Systems, Vol. 28, pp. 915-27, 2000.

[20] Kohler J L, Sottile J, Trutt F C, “Alternatives for assessing the electrical integrity of induction motors”, IEEE Transactions on Industry Applications, Vol. 28, No. 5, pp. 1109-17, 1992.

[21] Sottile J, Kohler J L, “An on-line method to detect incipient failure of turn insulation in random-wound motors”, IEEE Transactions on Energy Conversion, Vol. 8, No. 4, December, pp. 762-768, 1993.

[22] Kohler J L, Sottile J, Trutt F C, “Condition monitoring of stator windings in induction motors: Part I - Experimental investigation of the effective negative-sequence impedance detector", IEEE Transactions on Industry Applications, Vol. 38, No. 5, pp. 14471453, 2002.

[23] Trutt F C, Sottile J, Kohler J L, "Detection of electrical winding deterioration in induction motors", Electric Power Components and Systems, Vol. 19, No. 11, pp. 1025-33, 2001.

[24] Kohler J L, Sottile J, Trutt F C, “Condition monitoring of stator windings in induction motors: Part II - Experimental investigation of voltage mismatch detectors", IEEE Transactions on Industry Applications, Vol. 38, No. 5, pp. 1454-1459, 2002.

[25] Lee S B, Tallam R M, Habetler T G, “A robust, on-line turn-fault detection technique for induction machines based on monitoring the sequence component impedance matrix”, IEEE Transactions on Power Electronics, Vol. 18, No. 3, pp. 865-72, 2003. 